perchance yet hold lessons which have not hitherto received full recognition.

\title{
The visual requirements of military aviators
}

The great and growing importance of aviation from the military standpoint and the exacting nature of the work required obviously necessitate a standard of physical fitness different from that required for the ordinary soldier. The visual standard will also have to be superior. C. P. Small, of Chicago, in a recent paper (Jl. Amer. Med. Assoc., March 17, 1917), has raised the question and gives the standard that should be required as follows:-

" 1 . Uncorrected vision of $20 / 20$ in each eye. 2. Binocular vision. 3. Absence of nystagmus. 4. Normal muscle balance and competent ocular muscles. 5. Normal pupillary reaction and no pupillary irregularities when dilated. 6. Normal media and fundi. 7. Normal visual fields, by perimetric examination. 8. Normal colour sense."

In the body of the paper he asserts that every case must be examined with a mydriatic and comes essentially to the conclusion that nothing less than absolute perfection will do. E. Blaauw, of Buffalo, wrote a letter to the same journal, April 21, 1917, in which hc expressed doubts as to the necessity for good colour vision, binocular vision, and mydriatic examination. The correspondence was also carried on in the Ophthalmic Record, June, 1917, Blaauw, in that journal, pointing out the necessity of not being dogmatic from an ophthalmic point of view and of being guided by actual experience.

The problem in America is probably not quite the same as with us. The available material is greater, and no one will deny that the nearer perfection one can get the better. So, if Small's contention that nothing less than perfection will serve is correct, our part is rendered very simple, and the matter is at an end. But, before settling this point, it is worth considering what practical aviators have to say on the matter. We have notes of three cases of aviators, two of whom have been decorated for excellent work on the West front, with considerable amounts of mixed astigmatism. None of them wears his correction while flying, although that correction gives him normal vision in each eye, whereas when uncorrected the vision of the better eye is in one $6 / 9$, and in the other two 6/12, the vision of the worse eye being $6 / 18,6 / 36$, and $6 / 12$ respectively. In the one who has an eye with only $6 / 36$ there is imperfect binocular vision with a slight divergence.

It is obvious that successful flying can quite well be done with distant vision slightly below the normal. On the other hand, the necessity for quick and accurate reading of the dials of the various 
instruments renders the possession of good near vision absolutely essential; and, in our opinion, a low myope whose vision binocularly was $6 / 12$ would be, other things being equal, a more suitable candidate than a hypermetrope of any considerable degree, even though the distant vision of the latter was 6/5. We are not as yet in possession of sufficient knowledge of the efiects of flying at high altitude on the accommodation to be dogmatic on the point, but it seems quite possible that the rapid accommodative eftort necessary might not be available under such conditions.

It is not easy to define a satisfactory standard for binocular vision. Although it is a factor in the estimation of distance, it is not the only one, and many people who are not in possession of it judge distances with sufficient accuracy. Further information, derived from experience, would be necessary before laying down any rule on the matter.

Since more accidents occur through faulty landing than any other ordinary mistakes in flying, any defect of sight which might influence accurate judgment of position becomes of great importance. The possession of good binocular vision is certainly of great value in this connection. Successful landing is said to be almost instinctive, and certain aviators are stated to be unable to make good landings. It would be of great interest to know if in any such case binocular vision is defective.

All aviators with whom we have discussed the matter agree in the necessity for good colour vision. Signal lights have to be distinguished, particularly in making a night landing, and in ordinary observation work a colour-blind man may well make mistakes that might have most serious consequences.

Reaction time to visual impressions comes more under general than ocular examination. Small says that the French in their tests prefer the period to be in the neighbourhood of 19/100 of a second.

With the growing importance of night-flying the question of rapidity of dark adaptation needs discussion. After looking at the brightly illuminated dials of their instruments most aviators are unable to see anything outside for a considerable period. Some practical test of the rapidity with which the retina becomes dark adapted might be devised and found serviceable.

The present official standard for the R.F.C. is :-

Pilots-Better eye 6/12 with correction 6/6.

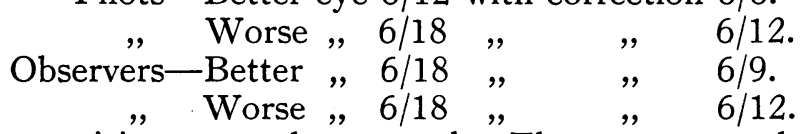

Colour vision must be normal. "The eyes must be free from disease. 